\title{
Surgical Treatment of Atrial Tachycardia Arising from Left Atrial Appendage
}

\author{
Taylan Adademir, Taylan Akgün'1, Ahmet Zengin, Alper Kepez², Kaan Kirali \\ Departments of Cardiovascular Surgery and ${ }^{1}$ Cardiology, Kartal Kosuyolu High Speciality Training and Research Hospital, ${ }^{2}$ Department of Cardiology, \\ School of Medicine, Marmara University, Istanbul, Turkey \\ ORCID: \\ Taylan Adademir: https://orcid.org/0000-0003-1643-3751 \\ Taylan Akgün: https://orcid.org/0000-0002-5395-2027 \\ Ahmet Zengin: https://orcid.org/0000-0002-9917-2181 \\ Alper Kepez: https://orcid.org/0000-0003-3868-3268 \\ Kaan Kirali: https://orcid.org/0000-0003-0044-4691
}

\section{Abstract}

Focal atrial tachycardia arising from the left atrial appendage (LAA) is less frequently encountered in clinical practice. Catheter ablation of this focal tachycardia is the main treatment and has a high success rate. Surgical radiofrequency isolation plus external closure of the appendage is an option in patients' refractory to catheter methods. An 18-year-old male patient was admitted to our hospital with a diagnosis of tachycardia-induced cardiomyopathy (ejection fraction 35\%). His electrophysiological study revealed a centrifugal activation pattern in the LAA where local atrial activation was earliest. Sinus rhythm was not achieved despite multiple attempts. Surgery was planned to isolate the source of the refractory arrhythmia. LAA of the patient was electrically isolated by using AtriCure ${ }^{\circledR}$ Synergy Ablation Clamp through the left anterior mini-thoracotomy. Sinus rhythm was restored right after successful isolation. AtriClip ${ }^{\circledR}$ PRO device was used to externally exclude the LAA to eliminate possible thrombus formation in isolated appendage. Surgical ablation methods are valid and successful options in patients who are refractory to medical and catheter methods. Dedicated arrhythmia teams (cardiologists, electrophysiologists, and cardiac surgeons) have the potential to increase patients' outcomes.

Keywords: Ablation, atrial tachycardia, surgery

\section{INTRODUCTION}

Atrial tachycardia (AT) is a relatively rare arrhythmia, accounting for approximately $7 \%$ of supraventricular tachycardias investigated at electrophysiologic study. ${ }^{[1]}$ AT typically arises from an ectopic source in the atrial muscle and produces an atrial rate of $150-250$ beats/min-slower than that of atrial flutter ${ }^{[2]}$ and is frequently unresponsive to medical therapy. ${ }^{[3]}$ Although endocardial mapping and radiofrequency ablation are very effective in diagnosis and treatment, ${ }^{[4]}$ surgical treatment is an option in cases where radiofrequency ablation fails. ${ }^{[5]}$

\section{Case Report}

A 18-year-old patient who admitted to our clinic with effort dyspnea has no attribute in physical examination. In

\begin{tabular}{|c|c|}
\hline \multicolumn{2}{|c|}{$\begin{array}{l}\text { Received: } 28-05-2020 \text { Revised: } 17-08-2020 \text { Accepted: } 21-09-2020 \\
\text { Published Online: } 27-11-2020\end{array}$} \\
\hline \multicolumn{2}{|c|}{ Access this article online } \\
\hline 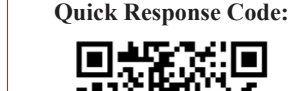 & $\begin{array}{l}\text { Website: } \\
\text { http://www.ijcva.com }\end{array}$ \\
\hline 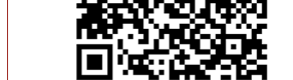 & $\begin{array}{l}\text { DOI: } \\
\text { 10.4103/IJCA.IJCA_28_20 }\end{array}$ \\
\hline
\end{tabular}

his anamnesis, he had no other features except orthopedic surgery due to an arm fracture. Laboratory workup revealed no predisposing factor for AT. Electrocardiography was consistent with AT [Figure 1] and ejection fraction was $35 \%$ on echocardiography. AT induced cardiomyopathy was considered, and percutaneous ablation was planned.

\section{Electrophysiology}

The patient was admitted to the electrophysiology laboratory with the diagnosis of incessant AT despite medical treatment (amiodarone $200 \mathrm{mg} 2 \times 1$, metoprolol $100 \mathrm{mg}$ $1 \times 1)$. Electrocardiogram $(\mathrm{ECG})$ showed AT and variable atrioventricular conduction with the ventricular rate of $109 / \mathrm{min}$.

Address for correspondence: Ahmet Zengin, Kartal Kosuyolu High Speciality Training and Research Hospital, Istanbul, Turkey. E-mail: dr.zenginahmet@gmail.com

This is an open access journal, and articles are distributed under the terms of the Creative Commons Attribution-NonCommercial-ShareAlike 4.0 License, which allows others to remix, tweak, and build upon the work non-commercially, as long as appropriate credit is given and the new creations are licensed under the identical terms.

For reprints contact: WKHLRPMedknow_reprints@wolterskluwer.com

How to cite this article: Adademir T, Akgün T, Zengin A, Kepez A, Kirali K. Surgical treatment of atrial tachycardia arising from left atrial appendage. Int J Cardiovasc Acad 2020;6:180-2. 
Electrophysiologic study was planned, and local anesthesia was applied with $20 \mathrm{cc}$ lidocaine via in the right and left femoral region. $7 \mathrm{~F}$ introducer vascular sheats were inserted into the right femoral vein by Seldinger method. Coronary sinus (CS), right ventricle, and His catheter were inserted. The atrial signals in CS distal electrode pairs were earlier than proximal. Electrophysiologic maneuvers confirmed AT with a cycle length of $260 \mathrm{~ms}$. The right atrium was mapped with three-dimensional electroanatomic mapping system (Biosense Webster, Diamond Bar, California) [Figure 2]. Sixty percent of Total Cycle Length (TCL) covered and the earliest site was septal. Transseptal puncture was performed considering left-sided AT. The left atrium was mapped, and the centrifugal activation pattern with the earliest signal in the left atrial appendage (LAA) was noted [Figure 3]. First, we tried to ablate earliest site in appendix with irrigated catheter at 35 watts but we failed. Then we tried to isolate LAA, but despite multiple applications, we couldn't succeed [Figure 4]. Surgical ablation was planned.

\section{Surgical technique}

Under general anesthesia, the LAA was exposed through the left anterior mini-thoracotomy incision. Single lung ventilation was achieved by a double-lumen endotracheal tube. Central venous pressure, systemic arterial pressure, and ECG were monitored throughout the procedure. After opening the pericardium, the LAA was explored. LAA of the

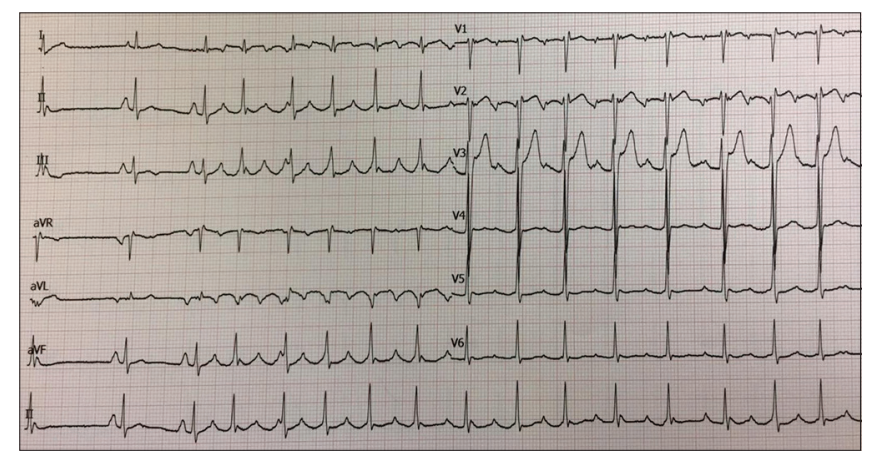

Figure 1: Preoperative electrocardiogram

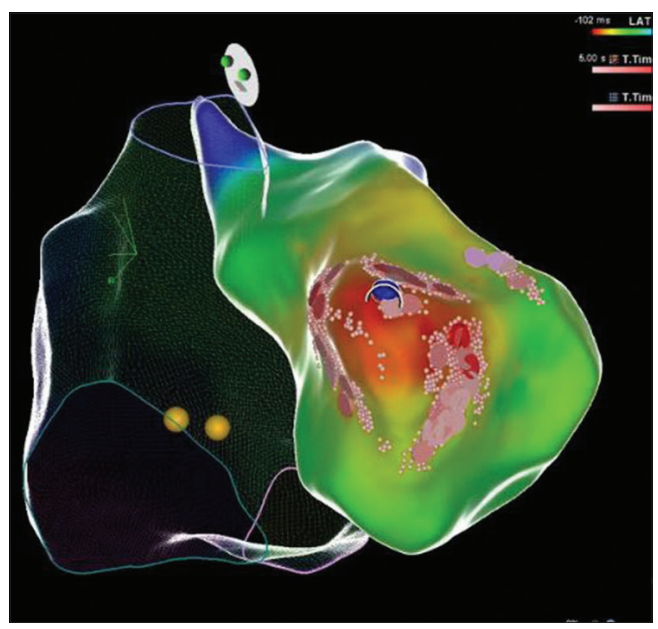

Figure 3: Activation map of the left atrium patient was electrically isolated from the rest of the left atrium by using AtriCure ${ }^{\circledR}$ Synergy radiofrequency ablation clamp. Sinus rhythm was restored right after successful isolation. AtriClip $^{\circledR}$ PRO Device was used to externally exclude the LAA to eliminate possible thrombus formation in isolated appendage [Figure 5].

\section{RESULTS}

After surgical ablation, the patient was followed in sinus rhythm without antiarrhythmic therapy [Figure 6]. In the postoperative early echocardiography, ejection fraction was measured $55 \%$. The patient was discharged on the $4^{\text {th }}$ postoperative day. At the $1^{\text {st }}$ month follow-up, the patient is followed in sinus rhythm without antiarrhythmic therapy and ejection fraction was measured $65 \%$ on echocardiography.

\section{Discussion}

AT is characterized by atrial activation starting rhythmically at a small area from where it spreads centrifugally. ${ }^{[6]}$ AT does not occur randomly throughout the atria, but rather cluster at predefined

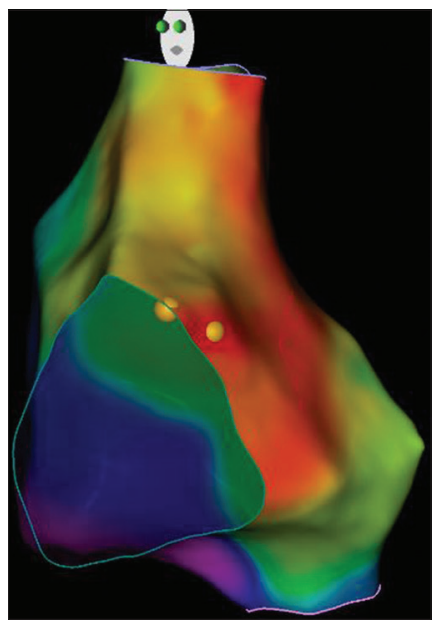

Figure 2: Activation map of the right atrium

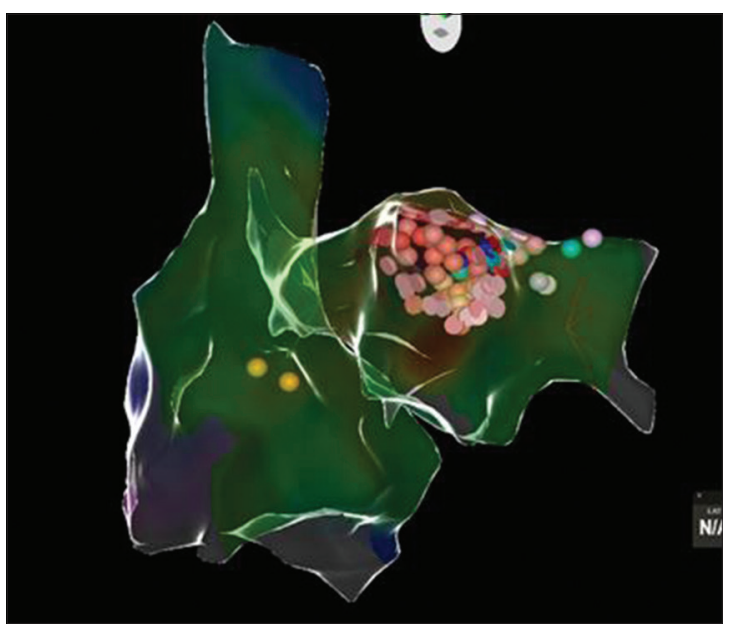

Figure 4: Ablation points 


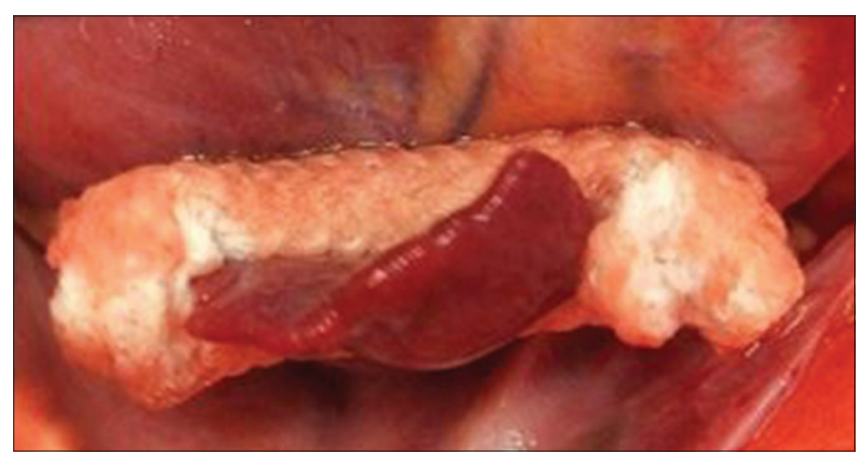

Figure 5: AtriClip ${ }^{\circledR}$ PRO Device

anatomic locations. ${ }^{[7]}$ These locations are characterized by alterations in myocardial fiber orientation or sites of automatic tissue. In a series of Kistler et al.,130 patients with clinically documented paroxysmal or incessant AT, $63 \%$ of ATs arose in the right atrium and $37 \%$ in the left atrium. The distribution of sites of origin among the right ATs was; tricuspid annulus (35\%), crista terminalis (34\%), CS ostium (17\%), perinodal tissues (9\%), right atrial appendage (4\%). Left ATs were predominantly located around the pulmonary veins $(67 \%)$. Less common sites of origin include the mitral annulus (17\%), CS body (6\%), left interatrial septum (6\%), and the LAA (4\%). ${ }^{[8]}$ Anguera et al. published results of AT that treated with percutaneous ablation and achieved successful results in $77 \%$ of 105 patients, but $23 \%$ did not respond to treatment. ${ }^{[9]}$

Endocardial mapping and radiofrequency ablation have a high success rate in the treatment AT and nowadays are used as the primary treatment in diagnosis and treatment. Despite the effective use, radiofrequency ablation may fail in less common origins, such as the LAA. The internal surface of the LAA is composed of pectinate muscles, which result in an uneven surface in contrast to the relatively smooth walls of the rest of the left atrium. Therefore, LAA isolation is challenging and it often requires to redo ablation. Surgical ablation, which provides a significant clinical and echocardiographic improvement in patients after failed percutaneous ablation, should be kept in mind as an easily applicable and fast effective option.

ECG may help localizing focal ATs arising from LAA by negative $P$ wave morphology in lead I, positive in lead II, III and arteriovenous fistula, positive in V1 through V3 and isoelectric in lateral precordials as shown in our patient also.

Surgical ablation methods are valid and successful options in patients who are refractory to medical and catheter methods. Dedicated arrhythmia teams (Cardiologists, electrophysiologists, and cardiac surgeons) have the potential to increase patients' outcomes.

\section{Declaration of patient consent}

The authors certify that they have obtained all appropriate patient consent forms. In the form the patient(s) has/have given his/her/their consent for his/her/their images and other

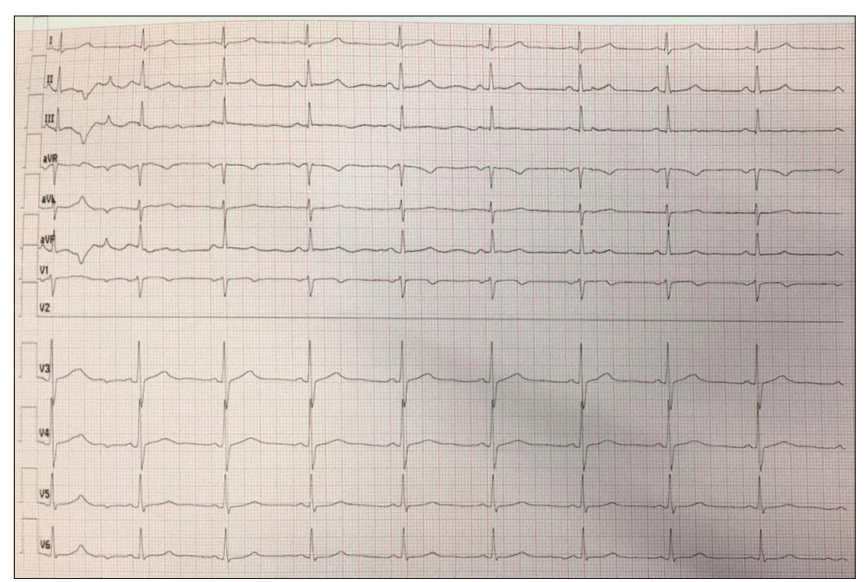

Figure 6: Postoperative electrocardiogram

clinical information to be reported in the journal. The patients understand that their names and initials will not be published and due efforts will be made to conceal their identity, but anonymity cannot be guaranteed.

\section{Financial support and sponsorship}

Nil.

\section{Conflicts of interest}

There are no conflicts of interest.

\section{REFERENCES}

1. Ross DL, Denniss AR, Uther JB. Electrophysiologic study in supraventricular arrhythmias. Cardiovasc Clin 1985;15:187-213.

2. Goodacre S, Irons R. ABC of clinical electrocardiography: Atrial arrhythmias. BMJ 2002;324:594-7.

3. Poty H, Saoudi N, Haïssaguerre M, Daou A, Clémenty J, Letac B. Radiofrequency catheterablation of atrial tachycardias. Am Heart $\mathrm{J}$ 1996;131:481-9.

4. Chen SA, Chiang CE, Yang CJ, Cheng CC, Wu TJ, Wang SP, et al. Sustained atrial tachycardia in adult patients. Electrophysiological characteristics, pharmacological response, possible mechanisms, and effects of radiofrequency ablation. Circulation 1994;90:1262-78.

5. Wyndham CR, Arnsdorf MF, Levitsky S, Smith TC, Dhingra RC, Denes $\mathrm{P}$, et al. Successful surgical excision of focal paroxysmal atrial tachycardia. Observations in vivo and in vitro. Circulation 1980;62:1365-72.

6. Saoudi N, Cosío F, Waldo A, Chen SA, Iesaka Y, Lesh M, et al. A classification of atrial flutter and regular atrial tachycardia according to electrophysiological mechanisms and anatomical bases; a Statement from a Joint Expert Group from The Working Group of Arrhythmias of the European Society of Cardiology and the North American Society of Pacing and Electrophysiology. Eur Heart J 2001;22:1162-82.

7. Kistler PM, Sanders P, Hussin A, Morton JB, Vohra JK, Sparks PB, et al. Focal atrial tachycardia arising from the mitral annulus: Electrocardiographic and electrophysgiologic characterization. J Am Coll Cardiol 2003;41:2212-9.

8. Kistler PM, Roberts-Thomson KC, Haqqani HM, Fynn SP, Singarayar S, Vohra JK, et al. P-wave morphology in focal atrial tachycardia: Development of an algorithm to predict the anatomic site of origin. J Am Coll Cardiol 2006;48:1010-7.

9. Anguera I, Brugada J, Roba M, Mont L, Aguinaga L, Geelen P, et al. Outcomes after radiofrequency catheter ablation of atrial tachycardia. Am J Cardiol 2001;87:886-90. 